Recibido: 14/05/2021 --- Aceptado: 06/09/2021 --- Publicado: 10/12/2021

\title{
COVID-19 E INSTAGRAM: UMA ANÁLISE DAS PUBLICAÇÕES IBERO-AMERICANAS
}

\section{COVID-19 AND INSTAGRAM: AN ANALYSIS OF IBERO- AMERICAN PUBLICATIONS}

(D) Denis Renó ${ }^{1}$ : Universidade Estadual Paulista. Brasil. denis.reno@unesp.br

(83) Xabier Martínez-Rolán²: Universidade de Vigo. España. xabier.rolan@uvigo.es

(3) Teresa Piñeiro-Otero ${ }^{3}$ : Universidade da Coruña. España. teresa.pineiro@udc.es

Andrea Versuti ${ }^{4}$ : Universidade de Brasília. Brasil. andrea.versuti@gmail.com

\section{Cómo citar el artículo:}

Renó, D., Martínez-Rolán, X., Piñeiro-Otero, T. y Versuti, A. (2021). Covid-19 e Instagram: uma análise das publicações ibero-americanas. Revista de Comunicación de la SEECI, 54, 223-248. http://doi.org/10.15198/seeci.2021.54.e724

1 Denis Renó: Periodista y documentalista, Doctor en Comunicación Social por la Universidad Metodista de São Paulo (Brasil). Es profesor del Programa de Periodismo de la Facultad de Arquitectura, Artes y Comunicación de la Universidad Estadual Paulista - UNESP (Brasil).

denis.reno@unesp.br

${ }^{2}$ Xabier Martínez-Rolán: Licenciado en Comunicación Audiovisual y Doctor en Comunicación por la Universidade de Vigo. Profesor del Departamento de Publicidad y Comunicación Audiovisual de la Universidade de Vigo.

xabier.rolan@uvigo.es

${ }^{3}$ Teresa Piñeiro-Otero: Licenciada en Publicidad y Relaciones Públicas y Doctora en Comunicación por la Universidade de Vigo. Profesora del Departamento de Sociología y Ciencias de la Comunicación de la Universidade da Coruña.

teresa.pineiro@udc.es

${ }^{4}$ Andrea Versuti: Doutora em Educação Ciência e Tecnologia pela UNICAMP. Professora da área de Educação, Tecnologias e Comunicação da Faculdade de Educação da Universidade de Brasília (UnB). Membro do Grupo de Pesquisa Educação, Filosofia e Imagem (GEFI).

andrea.versuti@gmail.com 
Investigação financiada pelo Conselho Nacional de Desenvolvimento Científico e Tecnológico - CNPq, processo número 401041/2020-4.

Financiamento: Esta investigação forma parte do projeto "Educar e informar: a fotografia nos processos comunicacionais via Instagram sobre o COVID-19" (número de referencia 401041/2020), financiado pelo Conselho Nacional de Desenvolvimento Científico e Tecnológico (CNPq), en colaboração com o Ministério da Ciência, Tecnologia, Inovações e Comunicações (MCTIC), e o Ministério da Saúde (MS) de Brasil.

\section{RESUMO}

Compreender o papel da comunicação promovida pela sociedade ibero-americana durante a pandemia do Coronavírus é algo fundamental para a construção do conhecimento sobre a doença. Neste cenário, o Instagram ocupa um lugar privilegiado, pois carrega uma diversidade de linguagens possíveis. Ademais, a relevância do Instagram no cenário das redes sociais é crescente. Este artigo apresenta, a partir de um estudo desenvolvido através de procedimentos de análise do Big Data, um primeiro resultado de vários que compõem uma investigação internacional sobre a temática. Na etapa do projeto, foram constatadas o volume quantitativo das publicações, a média de publicação por utilizador e as participações das diversas linguagens empregadas neste grupo de análise. Espera-se que novas investigações possam ser desenvolvidos a partir dos resultados aqui apresentados, especialmente pela urgência de se conhecer o papel da comunicação no cenário de pandemia no qual vivemos.

PALAVRAS CHAVE: Comunicação - Fotografia - Instagram - Big Data - COVID-19 - coronavirus - panedemia.

\section{ABSTRACT}

Understanding the role of communication promoted by Ibero-American society during the Coronavirus pandemic is fundamental to the construction of knowledge about the disease. In this scenario, Instagram occupies a privileged place, as it carries a diversity of possible languages. In addition, Instagram's relevance in the social networking landscape is growing. This article presents, from a study developed through big data analysis procedures, a first result of several that make up an international investigation on the subject. At the stage of the project, the quantitative volume of publications, the average publication per user and the participation of the various languages used in this analysis group were verified. It is expected that further investigations can be developed from the results presented here, especially due to the urgency of knowing the role of communication in the pandemic scenario in which we live.

KEY WORDS: Communication - Photography - Instagram - Big Data - COVID-19 - coronavirus - pandemic. 


\section{COVID-19 E INSTAGRAM: UN ANÁLISIS DE PUBLICACIONES IBEROAMERICANAS}

\section{RESUMEN}

Comprender el papel de la comunicación promovido por la sociedad iberoamericana durante la pandemia del Coronavirus es fundamental para construir conocimiento sobre la enfermedad. En este escenario, Instagram ocupa un lugar privilegiado, ya que lleva una diversidad de lenguajes posibles. Además, la relevancia de Instagram en el panorama de las redes sociales está creciendo. Este artículo presenta, a partir de un estudio desarrollado mediante procedimientos de análisis de Big Data, el primer resultado de varios que conforman una investigación internacional sobre el tema. En la etapa de proyecto se verificó el volumen cuantitativo de publicaciones, la publicación promedio por usuario y la participación de los diferentes idiomas utilizados en este grupo de análisis. Se espera que se puedan desarrollar más investigaciones a partir de los resultados aquí presentados, sobre todo por la urgencia de conocer el papel de la comunicación en el escenario pandémico en el que vivimos.

PALABRAS CLAVE: Comunicación - Fotografia - Instagram - Big Data - COVID-19 coronavirus - pandemia.

\section{INTRODUCCIÓN}

A sociedade contemporânea vivencia transformações expressivas em diversos setores, especialmente a partir do advento das tecnologias digitais. Os cidadãos, imersos em comportamentos líquidos (Bauman, 2001) e conectados por redes de relacionamento (Castells, 2000), compõem um cenário cada vez mais imagético, como já esperava McLuhan (1964) ao analisar a televisão à época. Entretanto, com o surgimento da internet e de dispositivos móveis, o uso da imagem como linguagem comunicacional entre pessoas (P2P) foi potencializado, e as redes sociais passaram a valorizar ainda mais esse tipo de recurso. Nesse aspecto, a narrativa imagética vivencia processos mutantes expressivos desde o advento da tecnologia digital, tornando-se importante protagonista nos processos comunicacionais em espaços participativos, como o Instagram.

Com a pandemia provocada pelo COVID-19, o Instagram vive um crescente protagonismo entre as redes de relacionamento sustentadas pelas mídias sociais. Segundo o Digital 2021 global overview em janeiro de 2021 situava-se como a quinta plataforma social mais popular, com uma comunidade global de 1.221 milhões pessoas (WeAreSocial \& Hootsuite, 2021).

Através do Instagram os utilizadores têm ocupado um papel destacado no sentido de expor seus sentimentos, desejos, opiniões e aflições sobre a pandemia. $O$ seu componente visual facilitou o seu papel na construção das narrativas de pandemia, possibilitando o contato e conexão das pessoas utentes, além do seu efeito 
emocional (Cho et al., 2018) e motivacional (Kamel, Giustini \& Wheeler, 2016; Chung et al. 2017).

Desde uma perspectiva social, o Instagram possibilita o emprego dos recursos para o

[...] acesso a informações oficiais no momento do entretenimento; a comparação das informações veiculadas em diferentes perfis; a validação de informações da mídia massiva; a partilha dos sentimentos coletivos por meio de imagens e vídeos; e o vínculo semi-íntimo com influenciadores profissionais de saúde (Pinto et al., 2020, p. 45)

Embora Igartua, Ortega Mohedano e Arcila Calderón (2020) situam o Instagram dentro das redes sociais de maior componente visual, com uma orientação para a captura de likes mais que à informação, a combinação de entretenimento com conteúdos informativos e inclusive pedagógicos gera um espaço propício para a comunicação sanitária quase no mesmo plano que outras redes (Garcia \& EiróGomes, 2020). Assim foram diversos os estudos que analisaram o papel do Instagram para a comunicação de saúde (Kamel Boulous, Giustini \& Wheeler, 2016; Fung et al., 2020) no enquadramento de crises de saúde pública (Setlzer et al., 2015; Setlzer et al., 2017; Guidy et al., 2017; Fung et al., 2017 ou Guidy et al. 2019).

Porém, no mesmo cenário em que a imagem ganha protagonismo, encontramos a desinformação disseminada pelas mesmas redes de relacionamento, algo que em um momento de pandemia torna-se ainda menos desejável. Conjuntamente à crise sanitária, instituições públicas e organismos de saúde tiveram que fazer frente à infodemia para a contenção do vírus (Aleixandre-Benavent et.al., 2020), ao mesmo tempo que o fenômeno dos fact-checkers cresceu nos últimos anos de forma paralela à desinformação (Dafonte-Gómez et al. 2019).

De fato, se em situações pré-COVID este crescimento de notícias falsas dificulta enormemente o esforço por obter informação por parte da sociedade (CaseroRipollés, 2020), e inclusive com o esforço dos governos para melhorar e ampliar a sua comunicação em relação à COVID-19 - em especial o caso da Espanha e suas coletivas de imprensa durante o confinamento, analisados por Castillo-Esparcia et al. (2020), a opinião pública segue seus próprios padrões de informação e compartilhamento da mesma em todas as redes sociais. Não se pode dizer o mesmo no caso do Brasil, pois o Governo Federal seguiu totalmente desalinhado da ciência, inclusive com o compartilhamento de notícias falsas sobre tratamentos comprovadamente ineficazes contra o COVID-19 e também sobre a importância do uso de máscaras e a prática do distanciamento social. Isso gerou um alto número de mortos, que no momento de redação deste artigo se aproximava de 560 mil vítimas.

Esta investigação, que apresenta através deste artigo os resultados quantitativos observados nas publicações ibero-americanas no Instagram registradas no início da pandemia. Para tanto, foram coletadas as publicações em português e espanhol entre 13 de março e 20 de maio de 2020 que continham as hashtags \#covid19 e 
\#coronavirus, totalizando 103.775 publicações feitas por 13.051 utilizadores. A seleção das etiquetas como objeto de estúdio nos situa na linha de trabalhos como o de Wagner, Marcon \& Caulfiel (2020) sobre o hashtag \#immunebooster. Isso foi tendência nesta rede social, ou o Nikmam et al. (2021), que analisaram a conversa social articulada em torno à \#COVID-19, (Caldevilla-Domínguez et al., 2021), inclusive durante a quarentena (Lucibello et al. 2021; Barrientos-Báez et al. 2021). Sobre redes sociais e COVID destacam também os trabalhos de Orduña-Malea et al. (2020) relativos a vídeos.

Com base em recursos de visualização de dados proporcionados pela plataforma Graphext, observamos quantitativamente e qualitativamente essas publicações e apresentamos tais resultados para que possamos, a partir deste primeiro momento de observação, compreender o papel das redes de relacionamento existentes na mídia social Instagram nos primeiros meses de pandemia, nomeadamente nos países ibero-americanos. Espera-se, com a conclusão deste artigo, oferecer subsídios para novos estudos relacionados à temática, assim como a contemplação de condições para que soluções contra a desinformação sejam encontradas.

\subsection{Redes de relacionamento em espaços digitais}

Na sociedade contemporânea, as mudanças culturais e tecnológicas estão cada vez mais presentes e incisivas no cotidiano dos sujeitos. As diferentes formas de comunicação sofrem enorme impacto com as mudanças decorrentes das inúmeras tecnologias digitais de comunicação e informação disponíveis.

O espaço no qual isso acontece é denominado ciberespaço, espaço dos novos meios de comunicação que surge a partir da internet. $O$ termo ciberespaço contempla não só a infraestrutura dos materiais tecnológicos, mas também os conteúdos e sujeitos que transitam e estão imersos nele, respectivamente. Diante deste contexto digital, novos modos de ser, sentir, relacionar e conhecer se tornam acessíveis aos sujeitos, nascendo então a cibercultura (ou cultura digital) na qual os sujeitos relacionam-se e compartilham conteúdos por meio de diferentes mídias, de forma instantânea, participativa e colaborativa. Segundo Levy (2010, p. 17), a cibercultura é "o conjunto de técnicas (materiais e intelectuais), de práticas, de atitudes, de modos de pensamento e de valores que se desenvolvem juntamente com o crescimento do ciberespaço".

No ciberespaço fazemos tudo que fazem as pessoas quando se encontram, mas o fazemos com palavras, imagens, vídeos e nas telas das interfaces computacionais. A partir dele, podemos pensar que os signos de um meio criam, geram, constroem outros signos em meios diferentes demonstrando com isso a possibilidade de uma semiose ilimitada. No mundo todo, bilhões de pessoas pertencem a alguma rede social digital na qual nossas identidades se misturam e interagem eletronicamente, independente do tempo e do local (Santaella, 2013, p. 123). Importante dizer também que neste contexto, os marcadores sociais da diferença: condição sócioeconômica e cultural, raça, gênero e geração estão presentes e se manifestam efetivamente no âmbito das relações estabelecidas pelos sujeitos. 
A cultura digital contempla a criação/produção de conteúdos em suportes midiáticos e a intensificação da interconexão que pode haver entre esses conteúdos. Diversas mídias fazem com que as pessoas se conectem através de diferentes plataformas que se agrupam num único dispositivo, o que nos permite falar de convergência. Esta convergência não apenas se arquiteta na evolução das mídias, nem tampouco a respeito do que elas se nomeiam a apresentar de inédito enquanto utilização, mas sobretudo traz mudança significativa nos paradigmas das relações sociais, culturais e de consumo, estabelecendo um modo expandido de integrar e interagir com diferentes conteúdos e informações disponíveis.

A convergência se caracteriza como uma transformação cultural que ocorre à medida que nasce a necessidade da busca de informação e conectividade aos conteúdos.

Para Jenkins (2009, p. 27), convergência é:

fluxo de conteúdos através de múltiplos suportes midiáticos, à cooperação entre múltiplos mercados midiáticos e ao comportamento migratório dos públicos dos meios de comunicação, que vão a quase qualquer parte em busca das experiências de entretenimento que desejam. [...] consegue definir transformações tecnológicas, mercadológicas, culturais e sociais [...]

As interações presentes no contexto digital não acontecem apenas pelo aparato tecnológico mas acontecem, principalmente, pelos modos pelos quais os sujeitos se apropriam das tecnologias para produzir cultura. Na cultura digital o sujeito é o centro do processo, pelo fato de fazer o conteúdo convergir em diferentes plataformas de mídia e, também, se fazer presente nesses diferentes espaços. A mídia é importante, pois é o suporte que contribuiu para as mudanças nas ações dos sujeitos nela imersos, porém sem a mudança na percepção do sujeito não seria possível desenvolver as interações no ciberespaço.

O mais relevante é, portanto, compreender como se constrói e se traduz a relação dos sujeitos culturais com essas mídias. Um destes processos mais evidentes é o de virtualização da identidade pessoal. Com ela surgem os perfis virtuais que libertam a entidade das amarras do espaço-tempo:

A virtualização não é uma desrealização (a transformação de uma entidade num conjunto de possíveis), mas uma mutação de identidade, um deslocamento do centro de gravidade ontológico do objeto considerado: em vez de se definir principalmente por sua atualidade (uma 'solução'), a entidade passa a encontrar sua consistência essencial num campo problemático. (Lévy, 2011, p. 17-18)

Assim, entendemos que a convergência é um processo que permite a fluidez entre as mídias e linguagens possibilitando acesso a diferentes informações e conteúdos que podem colaborar para a estruturação do conhecimento que rompe com a barreira definida para cada mídia e passa a complementar umas com as outras 
favorecendo que os sujeitos busquem informações em diferentes fontes, integrandoas.

De acordo com Santaella (2005), com a convergência digital as transmutações de conteúdos ocorrem em incontáveis versões virtuais que vão surgindo à medida que o receptor se coloca em posição de coautor. Sendo assim, há também uma soma qualitativa das matrizes da linguagem e do pensamento, sejam elas sonoras, visuais e/ou verbais que vão dando novos sentidos às produções.

Toda nova linguagem traz consigo novos modos de pensar, agir, sentir. Brotando da convergência fenomenológica de todas as linguagens, a hipermídia significa uma síntese inaudita das matrizes de linguagem e pensamento sonoro, visual e verbal com todos os seus desdobramentos e misturas possíveis (Santaella, 2005, p. 392).

A partir desta contextualização, compreendemos que com a intensificação da conectividade entre os sujeitos possibilitada pela convergência digital surgem novas maneiras para que a construção do conhecimento se efetive. Estes novos modos passaram a se pautar pelo aumento exponencial de algumas características substantivas das informações disponíveis nos meios digitais tais como; a multiplicidade de linguagens nas quais se constituem, a diversidade de fontes, 0 volume, a quantidade, o alcance, a abrangência e escala, a pluralidade de opiniões e o fenômeno mundial de polarização política/ideológica, além do enfrentamento constante da desinformação.

Este cenário bastante complexo afeta de forma incisiva algumas esferas sociais; como o mundo do trabalho, o gerenciamento político, o investimento em ciência e tecnologia, a agenda ambiental, o consumo, a comunicação, as pautas progressistas em defesa dos direitos sociais fundamentais, as relações interpessoais e também a educação. Enfim, toda nossa cultura está em processo constante de mudança (qualitativa e quantitativa) com a participação cada vez mais intensiva e extensiva dos meios digitais na realidade social.

O movimento de convergência digital potencializa as ações que podem ser realizadas em rede, algo que há quase duas décadas merece olhares atentos nos ambientes mediatizados é a conexão entre pessoas, popularmente conhecida como rede. Antes definida como uma reunião ou mobilização social em torno de um tema em comum, o conceito de rede passou a receber novas interpretações com 0 advento da Internet. O sociólogo espanhol Manuel Castells foi um dos pioneiros na interpretação dessa nova configuração social que passou a contar com ambientes mediatizados e, acima de tudo, a importância do cidadão nos processos de construção de redes.

Em sua obra "A Sociedade em Rede", Castells (2000) propõe a importância do Ser na sociedade da informação e os processos de comunicação baseadas na identidade das redes. Segundo Castells (2000, 57-58), "por identidade, entendo o processo pelo qual um ator social se reconhece e constrói significado principalmente com base 
em determinado atributo cultural ou conjunto de atributos, a ponto de excluir uma referência mais ampla a outras estruturas sociais".

É importante ressaltar que Castells não considera o conceito de rede como os acadêmicos da tecnologia consideram a mesma palavra. Ainda que a filosofia seja a mesma - redes de computadores ou redes sociais são interconectadas por diversos nós, sejam neurais, de processos ou de conexão física -, a rede proposta por Manuel Castells ultrapassa essa simplificação. Para o autor, uma rede social é apoiada em outras características, inclusive imateriais, como os interesses e objetivos mútuos. Essa rede social impulsiona mudanças coletivas, voluntária ou involuntariamente.

Numa obra mais atual, Castells (2013) apresenta o conceito de rede social com fins específicos de mobilização e mudança coletiva. Segundo o autor, "de fato, a mudança social envolve uma ação individual e/ou coletiva que é, em sua essência, emocionalmente motivada, da mesma forma que todo comportamento humano" (Castells, 2013, p.126).

Sobre esse tema, o autor também desmistifica a necessidade de tecnologia para a formação e a existência de redes. Para Castells, a tecnologia colabora e potencializa, mas o fundamental está no compartilhamento de interesses, necessidades e soluções.

São conectados em rede de múltiplas formas. $O$ uso das redes de comunicação na internet e dos telefones celulares é essencial, mas a forma de conectar-se em rede é multimodal. Inclui redes sociais on-line e off-line, assim como redes preexistentes e outras formadas durante as ações do movimento. Formam-se redes dentro do movimento, com outros movimentos do mundo todo, com a blogosfera da internet, com a mídia e com a sociedade em geral. As tecnologias que possibilitam a constituição de redes são significativas por fornecer a plataforma para essa prática continuada e que tende a se expandir, evoluindo com a mudança de formato do movimento. (Castells, 2013, p.128)

Ao debater a formação de redes, Manuel Castells valoriza a linguagem utilizada para compartilhar as ideias coletivas. Entre as mais destacadas, a imagem ocupa um status privilegiado no processo. Segundo Castells (2013, p.130), "o poder das imagens é soberano. O YouTube foi provavelmente uma das mais poderosas ferramentas de mobilização nos estágios iniciais do movimento". Efetivamente, para o autor, a imagem é protagonista de maior poder de mobilização e formação de redes, o que podemos observar a partir dos resultados quantitativos apresentados por esta investigação.

Entretanto, ao pensar sobre redes, no contexto desta investigação, devemos considerar o âmbito territorial. Porém, como proposto por Marc Augé (1994), nos ambientes digitais contamos com o não-lugar. A partir desta ideia, o teórico desenvolve uma leitura antropológica da sociedade contemporânea como uma rede de pessoas que habitam o não-lugar, pois tal não depende da condição física para se conectar. Para o autor, "O não-lugar é o espaço dos outros sem a presença dos outros, o espaço constituído em espetáculo" (Augé, 1994, p.167). O autor considera, 
em outro texto, que o não-lugar é o espaço comum do que ele define como sobremodernidade. E explica:

Mas, na medida em que o não lugar é o negativo do lugar, torna-se de fato necessário admitir que o desenvolvimento dos espaços da circulação, da comunicação e do consumo é um traço empírico pertinente da nossa contemporaneidade, que esses espaços são menos simbólicos do que codificados, assegurando neles toda uma sinalética e todo um conjunto de mensagens específicas (através de monitores, de vozes sintéticas) na circulação dos transeuntes e dos passageiros (Augé, 2006, p. 115).

Porém, a ideia de Augé não é suprema. Com outro olhar, o português Boaventura Sousa Santos (2005) defende uma posição intermediária entre o território geográfico e o virtual. Para o autor:

O tempo presente surge-nos como dominado por um movimento dialético em cujo seio os processos de globalização ocorrem de par com processos de localização. (...) as relações sociais em geral parecem estar cada vez mais desterritorializadas (...). Mas, por outro lado, e em aparente contradição com esta tendência, novas identidades regionais, nacionais e locais estão a emergir, construídas em torno de uma nova proeminência dos direitos às raízes. Tais localismos, tanto se referem a territórios reais ou imaginados, como a formas de vida e de sociabilidade assentes nas relações face a face, na proximidade e na interatividade. (Santos, 2005, p. 54)

Esses apontamentos direcionam a um entendimento fundamental para sustentar 0 valor das publicações encontradas por esta investigação. Percebe-se que há coerência espacial que traduz, de certa forma, a situação pandêmica nos países lusófonos e hispânicos. Torna claro, entretanto, que a relação entre os atores que compõem as redes pode existir a partir de conexões presenciais ou virtuais, especialmente se considerarmos o posicionamento de Boaventura Sousa Santos (2005), que nos traz a uma realidade mais ampla.

\section{OBJETIVOS}

O artigo em questão foi orientado por um objetivo geral a ser contemplado, que consistiu em descobrir o papel de conteúdos imagéticos na construção do discurso público sobre a COVID-19 nos países ibero-americanos. Para tanto, definiu-se o seguinte rol de objetivos específicos:

- Elaborar um Dataset suficientemente representativo para alcançar com segurança o objetivo geral;

- Constatar, quantitativamente, as publicações sobre COVID-19 durante o período determinado;

- Realizar uma análise quantitativa comparativa entre as publicações em português e espanhol registradas no período. 


\section{METODOLOGÍA}

Por se tratar de um artigo exploratório da investigação, que possui um complexo metodológico mais amplo, os dados aqui apresentados limitam-se a olhares quantitativos. Para tanto, desenvolve-se uma investigação de teor etnográfico, comumente adotada para compreender e explicar os fenômenos sociais e culturais contemporâneos. O método etnográfico, segundo Agrosino (2009, p.31), "(...) é baseado na pesquisa de campo (conduzido no local onde as pessoas vivem e não em laboratórios onde o pesquisador controla os elementos do comportamento a ser medido ou observado)". No artigo em questão, adotou-se o uso do método multifatorial, que tem como essência o uso de duas ou mais técnicas de coleta de dados. Para tanto, considera-se a netnografia, que consiste na coleta de dados da pesquisa etnográfica na internet (Turpo Gebera, 2008).

\section{1. $O$ corpus da investigação}

Esta investigação se centra no Instagram por ser a rede social com maior volume de impacto desde o ponto de vista imagético. Num momento em que a internet é eminentemente visual, os padrões de comportamento nas plataformas de gestão de redes sociais de imagens são expressivamente interessantes para analisar 0 comportamento da população por uma perspectiva macro.

A escolha de hashtags está relacionada com o seu papel na visibilidade de temáticas de comunicação. Um papel que também pode promover perspectivas de debate e impulsionar narrativas comuns (Rambukkana, 2015). Através dos hashtags, a comunicado multiplica e expande os nós de interconexão, ampliando as possibilidades de alcance das mensagens.

Ainda que Espanha e Brasil supõem unicamente dois dos países da esfera iberoamericana, adquiriram particular relevância na crise. De fato, seguindo a Rovetta \& Bhagavathula (2020), Brasil e Espanha são segunda e terceira nação mais citadas, em relação ao COVID-19, pela comunidade de usuários globais do Instagram (com 551.000 e 376.000 hashtags, respectivamente), o que leva a pensar em uma verdadeira polarização da conversa social.

Por esse motivo, o corpus da investigação se centra nas publicações realizadas nesta rede social, identificadas pelos hashtags \#covid e/ou \#coronavirus, realizadas em espanhol ou português (o sexto e o décimo primeiro idioma mais utilizados na rede e que abrangem uma ampla comunidade de usuários.

\subsection{O recorte temporal}

O período de coleta de dados compreende as publicações realizadas entre 13 de março e 20 de maio de 2020, justificado da seguinte maneira:

- O Governo da Espanha declarou em 13 de março o "Estado de Alarma", que duraria dois meses; no dia 20 de março o Senado Federal do Brasil aprovou o Decreto de Calamidade Pública. 
- O Governo da Espanha inicia a abertura em junho, colocando fim ao confinamento. O mesmo aconteceu gradualmente no Brasil, após dois meses de planos de distanciamento social.

\subsection{Ferramentas}

Para elaborar esta investigação, adotou-se o software CrowdTangle, que encontrou 103.775 publicações marcadas com as hashtags selecionadas (51.732 em espanhol e 48.746 em português, fica um $2 \%$ da amostra am outras línguas não detectadas pela plataforma), emitidas por um total de 13.051 utilizadores.

Para el proceso de extracción de datos se empleó la herramienta CrowdTangle (CrowdTangle Team, 2020), una aplicación nativa de Facebook que se integra perfectamente con las plataformas de esta empresa (incluído Instagram), que permite la extracción de los datos en formato .csv.

Para a análise de dados se optou por empregar a ferramenta Graphtext (s.f), ideal para a realização de análises complexas segundo a filosofia low-coding. Com a ferramenta, foi possível transformar os dados, explorá-los, visualizá-los e apresentar as suas descobertas a partir de um espaço de trabalho baseado em browser.

\section{RESULTADOS}

A primeira análise gráfica das publicações foi realizada com apoio do software Graphext, uma plataforma que permite criar gráficos e grafos a partir de big data em redes sociais. Na figura 1, observamos uma primeira representação do processo de coleta e cruzamento de dados, compostos por conteúdos em espanhol e português. É importante ressaltar que a segmentação em diferentes idiomas gerou dois macroclusters de publicações desconexas entre si. Isso se deve pelo fato das comunidades hispânica e lusófona possuírem interesses diferentes entre eles. 


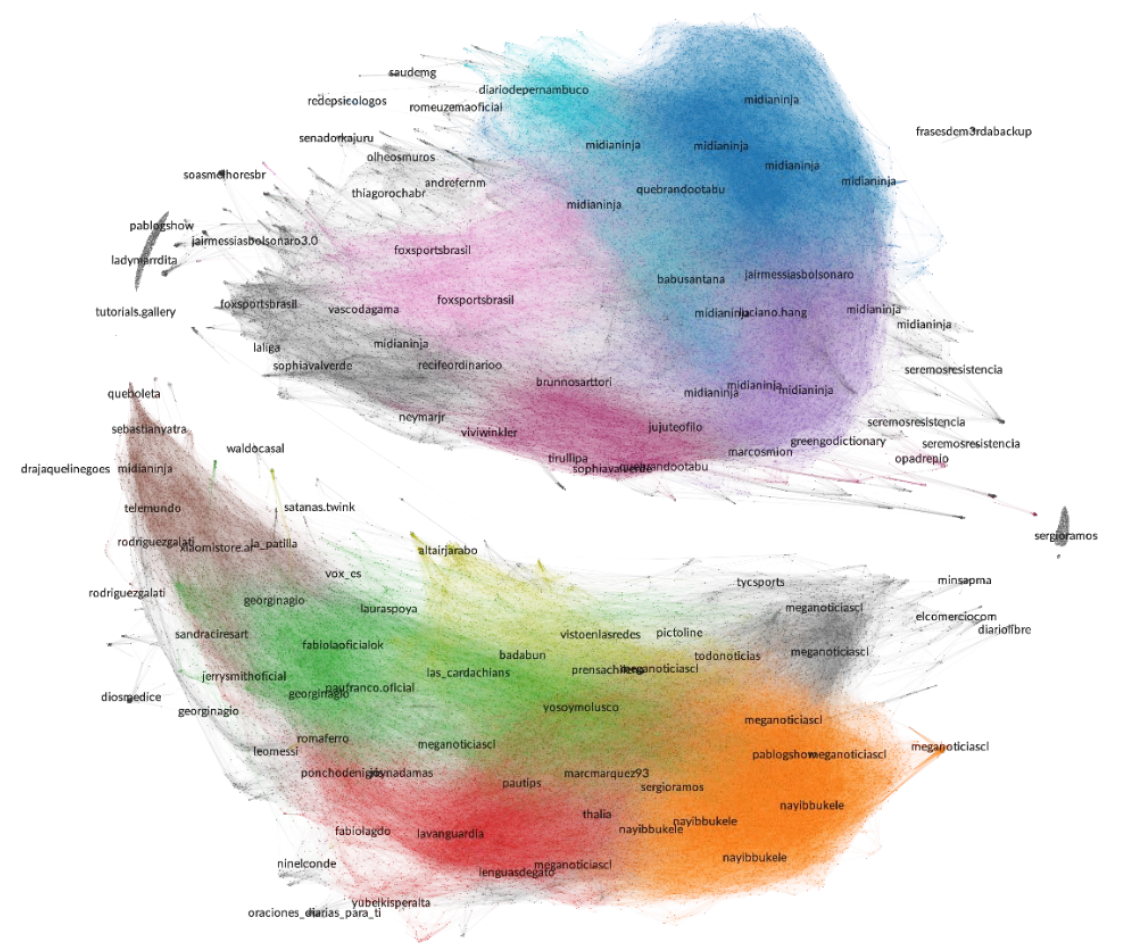

Gráfico 1: Mapa de publicações em português (em cima) e espanhol (embaixo)

Fonte: Graphext.

O cluster de publicações em espanhol é composta por 51.732 postagens no Instagram, enquanto a comunidade lusófona é representada por 48.746 postagens. É fundamental aclarar que a coleta também identificou $2 \%$ de casos de publicações em inglês ou idioma não definido pelo sistema.

Destacam-se em ambos clusters a aparição de nós (usuários) com um grande volume de publicação (descritos no gráfico 6), assim como a geração de diferentes grupos de usuários que se agrupam por diálogos, onde se observa o destaque de clusters comuns, ainda que desconexos entre as comunidades (quarentena/cuarentena, saúde/salud).

\subsection{Evolução temporal}

Assim como a relevância de publicações sobre escândalos midiáticos (Thompson, 2002), as publicações com as hashtags \#covid19 e \#coronavirus tiveram um ciclo claramente interpretado na figura 2. No começo do período analisado, observamos um forte crescimento das publicações marcadas pelas hashtags coincidindo com o decreto do Estado de Alarma na Espanha e em boa parte da Europa, ainda que com o tempo se observa o desgaste de publicações. Isso não ocorreu porque o coronavírus desapareceu, mas porque fala-se cada vez menos sobre o tema no Instagram. Um fenómeno que foi constatado por outros estudos sobre o uso das 
redes sociais na primeira fase da pandemia, por exemplo Hung et al. (2020), e que poderia se considerar com os primeiros sintomas de "fadiga pandêmica". Além disso, observa-se o ápice das publicações após o decreto de calamidade pública declarado pelo Governo do Brasil, coincidindo as mesmas preocupações em espanhol e português. Vale ressaltar que o vírus chegou na América Latina à mesma época que se manifestou no Brasil. O mesmo vale para Portugal e Espanha, que tiveram situações temporalmente parecidas.

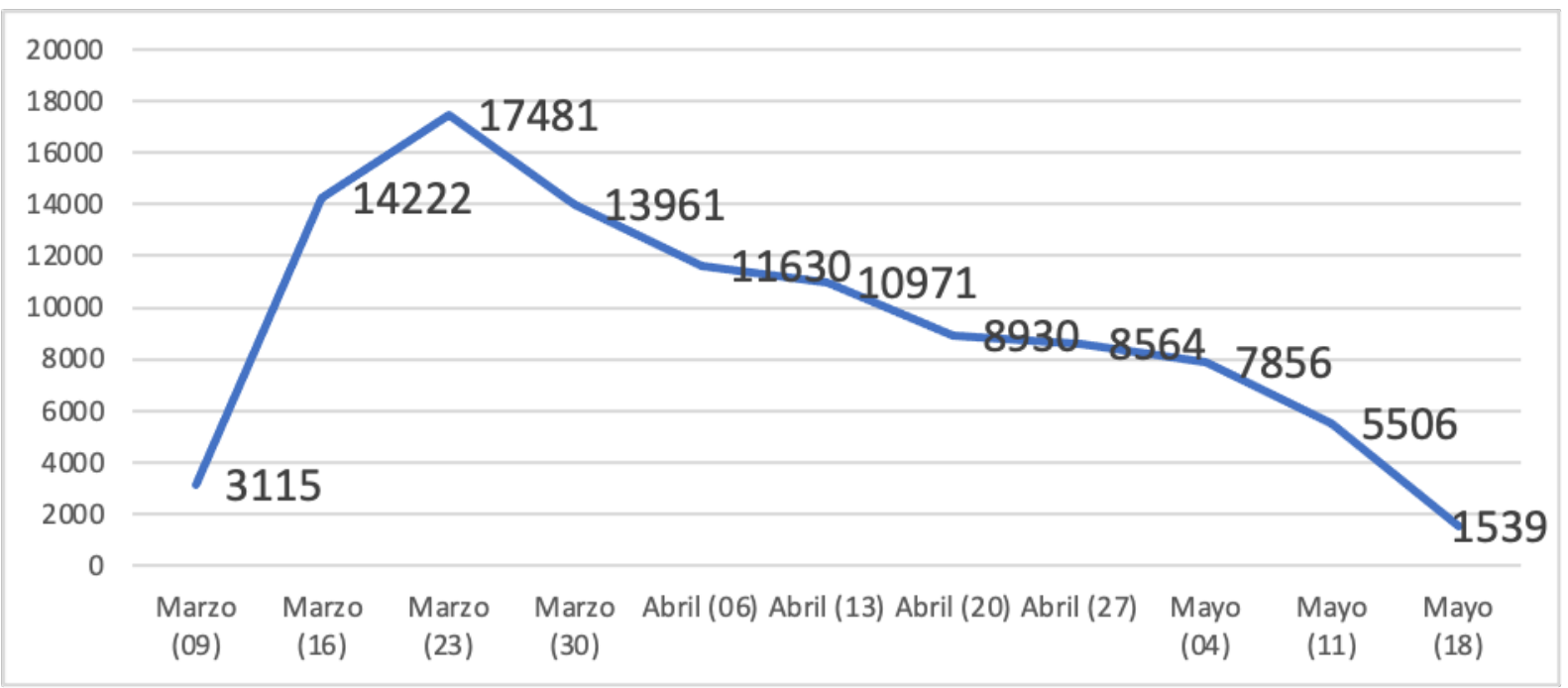

Gráfico 2: Evolução de publicações semanalmente

Fonte: Elaboração própria.

Entretanto, a figura 3 representa algo curioso. Diferentemente do analisado em outras investigações sobre o comportamento de utilizadores de redes sociais (Martínez-Rolán et al, 2019), se observarmos as publicações diárias percebemos uma queda de postagens com as hashtags nos fins de semana, quando o uso de redes sociais costuma ser mais intenso. Essa realidade merece observações detalhadas, qualitativamente, e sugere como uma possível explicação o descenso de pressão informativa dos meios de comunicação sobre o coronavirus, derivada da carência de dados e informação oficial nos fins de semana, que leva as pessoas a desenvolver atitudes mais habituais no Instagram, como a publicação e interação en torno a temas de lazer, menos preocupantes e/ou depressivos. 
Sanz-Marcos, P. Brand management y tribu consumidora. Un estudio aplicado a las marcas de surf españolas

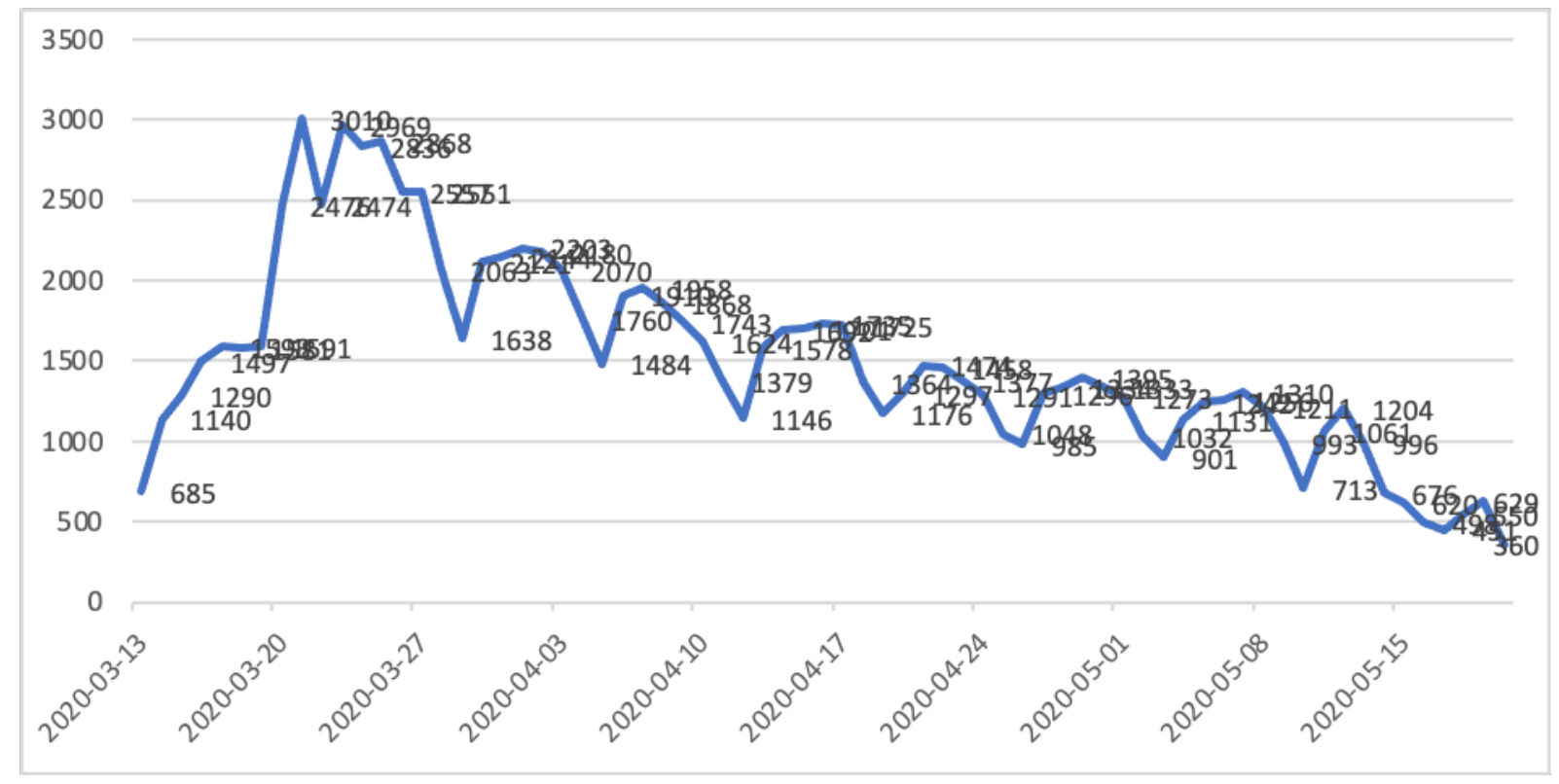

Gráfico 3: Evolução diária de publicações

Fonte: Elaboração própria. 
Sanz-Marcos, P. Brand management y tribu consumidora. Un estudio aplicado a las marcas de surf españolas

Tabela 1. Evolução diária de publicações

\begin{tabular}{|c|c|c|c|c|c|}
\hline Março & $\begin{array}{c}\mathrm{N}^{0} \\
\text { publicações/dia }\end{array}$ & Avril & $\begin{array}{c}\mathrm{N}^{0} \\
\text { publicações/dia }\end{array}$ & Maio & $\begin{array}{c}\mathrm{N}^{\mathrm{O}} \\
\text { publicações/dia }\end{array}$ \\
\hline $2020-03-13$ & 685 & 2020-04-01 & 2203 & 2020-05-01 & 1273 \\
\hline $2020-03-14$ & 1140 & 2020-04-02 & 2180 & 2020-05-02 & 1032 \\
\hline 2020-03-15 & 1290 & 2020-04-03 & 2070 & 2020-05-03 & 901 \\
\hline $2020-03-16$ & 1497 & 2020-04-04 & 1760 & 2020-05-04 & 1131 \\
\hline $2020-03-17$ & 1593 & 2020-04-05 & 1484 & 2020-05-05 & 1242 \\
\hline $2020-03-18$ & 1581 & 2020-04-06 & 1910 & $2020-05-06$ & 1256 \\
\hline 2020-03-19 & 1591 & 2020-04-07 & 1958 & 2020-05-07 & 1310 \\
\hline $2020-03-20$ & 2476 & 2020-04-08 & 1868 & 2020-05-08 & 1211 \\
\hline $2020-03-21$ & 3010 & 2020-04-09 & 1743 & 2020-05-09 & 993 \\
\hline $2020-03-22$ & 2474 & $2020-04-10$ & 1624 & $2020-05-10$ & 713 \\
\hline $2020-03-23$ & 2969 & 2020-04-11 & 1379 & $2020-05-11$ & 1061 \\
\hline $2020-03-24$ & 2836 & 2020-04-12 & 1146 & $2020-05-12$ & 1204 \\
\hline $2020-03-25$ & 2868 & 2020-04-13 & 1578 & $2020-05-13$ & 996 \\
\hline $2020-03-26$ & 2557 & 2020-04-14 & 1692 & $2020-05-14$ & 676 \\
\hline $2020-03-27$ & 2551 & 2020-04-15 & 1701 & 2020-05-15 & 620 \\
\hline $2020-03-28$ & 2063 & 2020-04-16 & 1735 & $2020-05-16$ & 498 \\
\hline $2020-03-29$ & 1638 & 2020-04-17 & 1725 & $2020-05-17$ & 451 \\
\hline $2020-03-30$ & 2121 & 2020-04-18 & 1364 & $2020-05-18$ & 550 \\
\hline $2020-03-31$ & \multirow[t]{12}{*}{2144} & 2020-04-19 & 1176 & 2020-05-19 & 629 \\
\hline & & 2020-04-20 & 1297 & $2020-05-20$ & 360 \\
\hline & & $2020-04-21$ & 1474 & & \\
\hline & & 2020-04-22 & 1458 & & \\
\hline & & 2020-04-23 & 1377 & & \\
\hline & & 2020-04-24 & 1291 & & \\
\hline & & 2020-04-25 & 1048 & & \\
\hline & & 2020-04-26 & 985 & & \\
\hline & & 2020-04-27 & 1296 & & \\
\hline & & 2020-04-28 & 1334 & & \\
\hline & & 2020-04-29 & 1395 & & \\
\hline & & 2020-04-30 & 1333 & & \\
\hline
\end{tabular}

Fonte: Elaboração própria

Este resultado é especialmente interessante, pois apesar de que praticamente todo o planeta estivesse confinado, inclusive os países ibero-americanos, os padrões de uso do Instagram, ao menos a nível de volume de publicação, revelaram uma tendência semanal em situações normais. Em melhores palavras, apesar de que todos os dias pareciam ser os mesmos (não era possível ou recomendável sair de casa), os declínios de publicação eram percebidos nos finais de semana. 
O confinamento e o desgaste aconteceram uma semana antes na Espanha, em comparação com o Brasil, o que se projetou na conversa social em torno às hashtags \#covid19 e \#coronavirus em Instagram. Como podemos perceber na figura 4, o desenho da curva de publicações acontece com uma semana de diferença entre os dois idiomas. Na Espanha, em especial, o confinamento encerrou-se em maio. Por essa razão, a curva de publicações diminuiu nessa época. O Brasil, por sua vez, continua em confinamento desordenado desde então, ainda que, curiosamente, a curva também tenha diminuido, provavelmente por um esgotamento social.

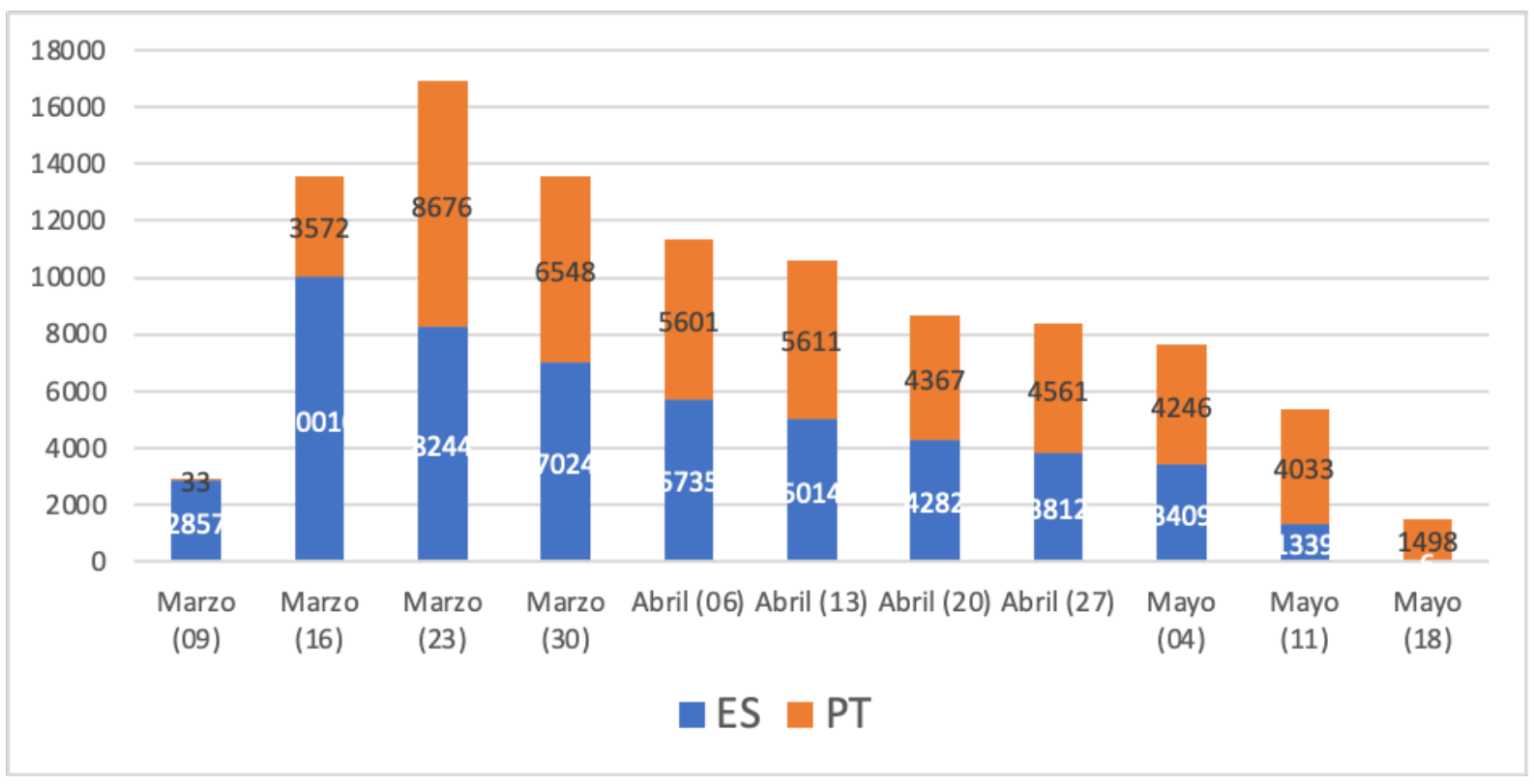

Gráfico 4: Evolução das publicações em espanhol e portugués

Fonte: Elaboração própria

Outro levantamento quantitativo interessante obtido nesta investigação refere-se ao tipo de conteúdo da publicação, já que o Instagram permite uma variedade de formatos que vão desde a fotografia ao audiovisual, passando por iconografia, textos e áudio. Além disso, é possível publicar um álbum de até 10 fotos e ainda realizar transmissões de vídeo ao vivo. Na coleta dos dados com as hashtags \#covid19 e \#coronavirus, obtivemos quatro viariedades de publicações em função da sua linguagem-forma com as seguintes classificações (Figura 6):

- Fotografias: uma única fotografia, acompanhada opcionalmente de um texto (caption);

- Álbum: um conjunto de duas ou mais fotografias acompanhada opcionalmente de um texto (caption);

- Vídeo: um fragmento de vídeo acompanhado opcionalmente por um texto (caption);

- Instagram TV: uma retransmissão de vídeo ao vivo, acompanhada opcionalmente por um texto (caption). 


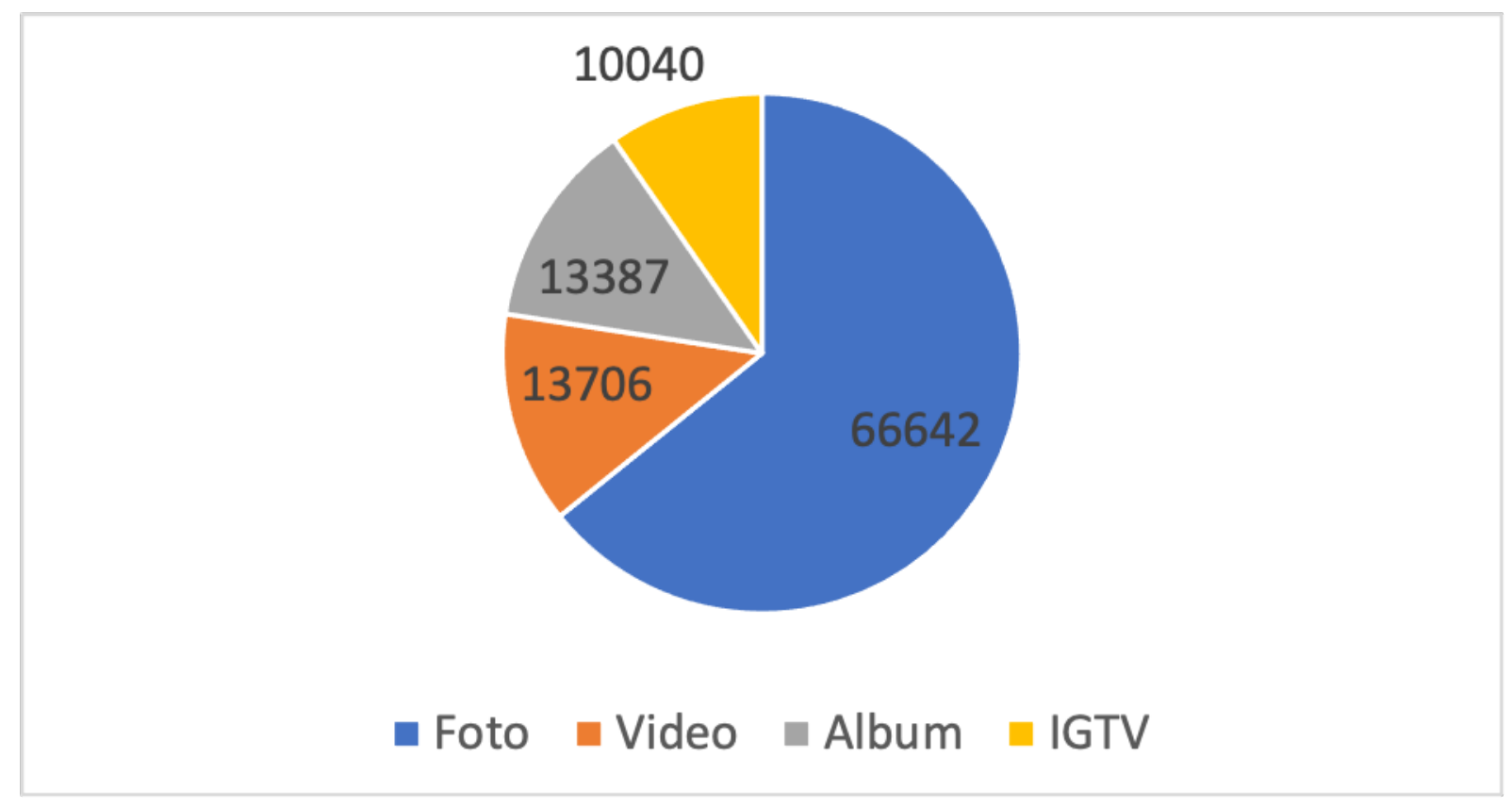

Gráfico 5: Variedades de publicações obtidas pela mostra

Fonte: Elaboração própria.

No escopo desta coleta, chama-nos a atenção a figura 7, com as cifras específicas para cada tipo de linguagem-forma adotada. Na seleção, observa-se uma predominância de fotografias que com 66.642 publicações (64\% dos post são imagens únicas). Essa cifra faz jus às origens da rede social. As fotografias constituem a forma mais singela de comunicar-se no Instagram e a favorita dos utilizadores quem compartilham ideias, pensamentos, inquietudes... condensados em uma única imagem que, acompanhada de um texto, criam um discurso multimodal sobre o que se estabelecem interações.

Os $36 \%$ das publicações restante (um total de 37.133 post) se distribuem de forma mais homogênea entre os outros tipos de linguagem-forma próprios do Instagram. Assim, com $13 \%$ da amostra, pode-se assinalar o equilíbrio prático entre as publicações com álbuns de fotos (uma expansão das fotografias presente em 13.387 publicações) e aquelas que utilizam vídeos para contribuir a sua perspetiva à narrativa coletiva da pandemia no Instagram (13.706 publicações).

Neste sentido, pode-se assinalar uma evolução positiva das publicações que empregam o formato audiovisual em Instagram. Pese a que as imagens estáticas fotos e álbuns - continuam detentando a prevalência das publicações desenvolto nestas plataformas, a crescente presença de vídeos e a rápida evolução das transmissões de vídeos no IGTV (10.040 publicações que já supõem o $10 \%$ da amostra analisada) permitem observar uma evolução na concepção e apropriação desta plataforma pela comunidade utilizadora.

Essa mistura de linguagens nos permite sustentar a ideia de que o Instagram é um espaço de mídia social pós-fotográfico, considerando o conceito apresentado por 
Joan Fontcuberta (2011). Para o autor, o ambiente de mediação contemporânea tem como característica a associação de diversas linguagens imagéticas como a fotografia, o audiovisual, o infográfico e a iconografia.

\subsection{Tipos de interação, média e mediana}

A amostragem da investigação é representada pelas 103.775 publicações, o que proporciona cifras de média e mediana elevadas. Autores como Sheldon e Bryant (2016) definiram o Instagram como uma rede centrada mais no pessoal que na identidade relacional. A realidade que no dia a dia da plataforma e as interações que se estabelecem nela se definiram determinadas personalidades (de diversa entidade off-line) com maior peso e influência na conversa social. Estes influencers - também do âmbito da saúde - se conformaram como verdadeiros líderes de opinião (Fregber et al., 2011) até o ponto de que algumas autoridades sanitárias solicitaram a sua colaboração na luta contra o vírus (Público, 2020), e a sua atuação na conversa social do Instagram tem sido objeto de estudo (Torres Romay e García Mirón, 2020).

Assim, a publicação com maior volume de interação da amostras, de autoria do jogador Leo Messi, possui, no momento da análise, 2.656.944 ações divididas entre likes e comentários. Em contrapartida, a que menos impacto recebeu foi a do deputado brasileiro Arnaldo Jardim, que alcançou 17 likes.

Como pode ser observado na tabela 1, ao considerar o total de publicações e interações recebidas, obtem-se uma média de 18.947 interações, com uma mediana de 3.232 interações. Os dados são relativamente elevados, pois o número de reproduções dos vídeos sempre é expressivo. Neste caso, deve-se considerar uma média de 55.831 reproduções (a mediana é sensivelmente inferior, com 24.165 reproduções).

Em contrapartida, as tradicionais formas de interação (likes e comentários) alcançaram cifras mais modestas, ainda que igualmente elevadas. A média de likes por publicação é de 4.982, acompanhadas de 59 comentários. Ainda que o número que mais se repete - mediana - é a publicação que contém 2.024 likes e 59 comentários. Isso representa um comentário para cada 34likes (mediana) oou cada 28 likes de média.

Tabela 2. Média e mediana dos tipos de interação

\begin{tabular}{|c|c|c|c|c|}
\hline & Likes & Comentários & Visualizações & Total Interações \\
\hline Média & 4.982 & 177 & 55.831 & 18.947 \\
\hline Mediana & 2.024 & 59 & 24.165 & 3.232 \\
\hline
\end{tabular}

Fonte: Elaboração própria

Os dados estão em sintonia com o que supõem os diferentes níveis de interação no Instagram: quanto maior é o esforço que requer a interação, menor é o volume de interações, e vice-versa. Assim, as reproduções (muito baixa interação) são muito 
mais que os likes (baixa interação), que, por sua vez, são menores que os comentários (média interação).

\subsection{Total de utilizadores e volume de participação}

Com um total de 103.775 publicações, foram contabilizados 13.051 utilizadores diferentes. Destes, aproximadamente metade dos utilizadores aparecem com uma única publicação: 6.326. Por outro lado, os demais 6.587 utilizadores que foram selecionados pela mostra são responsáveis pelas 97.449 publicações restantes. Valenos destacar que a distribuição desta participação é irregular e não respeita a média (14,7 publicações por utilizador).

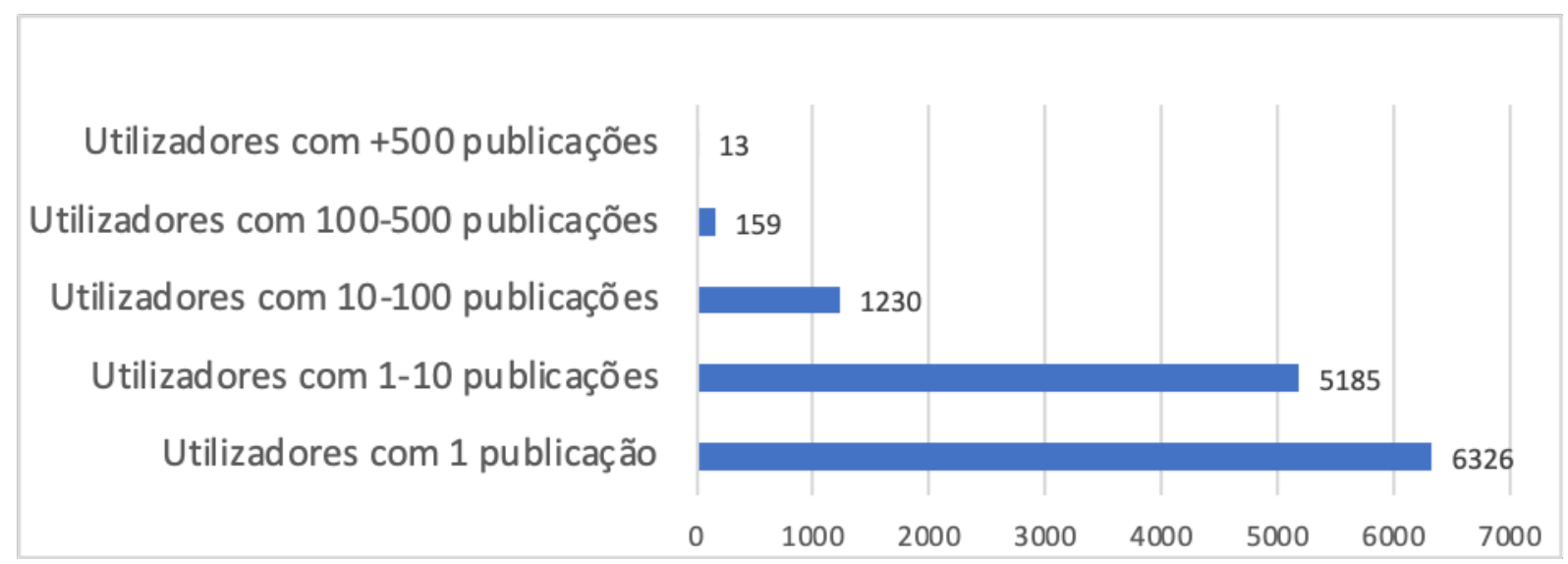

Gráfico 6: Volume de publicações por utilizador

Fonte: Elaboração própria.

Esta distribuição de usuários reflete uma descida logarítmica do número de mensagens enviadas, ao mesmo tempo que segue o princípio de Pareto, pois $20 \%$ dos usuários seria responsável por $80 \%$ das mensagens: poucos usuários são responsáveis pela maioria das mensagens da mostra.

\section{DISCUSIÓN}

Os dados obtidos a partir da metodologia empregada no estudo netnográfico demonstram uma relevância na observação do Instagram como espaço para compreensão do ecossistema midiático durante os primeiros dois meses da pandemia nos países falantes das línguas portuguesa e espanhola. Além de expressivas cifras, observa-se um desenho evolutivo semelhante nas duas regiões (lusófona e hispânica), nomeadamente Espanha e Brasil. De igual maneira, observase um disparo nas publicações logo após a declaração de Estado de Alarma pelo 
Governo da Espanha e o Decreto de Calamidade Pública pelo Senado Federal do Brasil.

É importante considerar que a comunidade hispânica é de 577 milhões em todo o mundo, enquanto a comunidade lusófona representa praticamente a metade, com 260 milhões de habitantes (48\%). Além disso, o Brasil possui 210 milhões de habitantes, o que representa quase a totalidade da amostragem lusófona.

Através do estudo aqui apresentado, observa-se que a fotografia continua sendo a linguagem protagonista do Instagram, com aproximadamente $60 \%$ do conteúdo coletado. Somadas as publicações de álbuns de fotografia, chegamos a quase $75 \%$ das publicações. Ainda assim, é importante recordar que um álbum pode conter fotografia e vídeo em um único álbum, o que pode alterar essa cifra.

Os resultados apresentados fortalecem a ideia de crescimento da narrativa imagética como linguagem contemporânea. Isso confirma, além da hipótese dessa investigação, indícios apresentados por Joan Fontcuberta (2011) ou mesmo Marshall McLuhan (1964), quando este último investigava influenciado pela televisão na sociedade da época.

Outra observação constatada nesta investigação refere-se ao volume de publicações. Considerando o total de publicações com as hashtags \#covid19 e \#coronavirus - 103.775 -, os 13.051 parecem ter publicado várias vezes. Entretanto, aproximadamente metade destes autores (6.587 pessoas) são responsáveis por 97.449 postagens, o que demonstra uma desigualdade de intensidade na participação. Essa diferença pode ser observada entre a postagem que recebeu mais participação (do jogador Lionel Messi, com 2.656.944 interações) com a postagem que recebeu menos participação (a do deputado federal brasileiro Arnaldo Jardim, com 17 interações). Isso demonstra que o autor do perfil ainda é fundamental, o que demonstra a possibilidade de se obter mais interação a partir de celebridades, em função da sua grande visibilidade, os que os torna influenciadores também no não lugar proposto por Augé (1994). Um médio que permitiu a criação de uma narrativa comum sobre a pandemia de caráter multimodal, na que informação de instituições e organismos públicos - como a analisada por Pinto et al. (2020) - se intercala, a diversos níveis, com experiências e vivências pessoais que, em tempos de solidão, se voltaram públicas e coletivas.

Porém, o estudo no qual este artigo está inserido ainda tem procedimentos a serem cumpridos. Este artigo propõe uma base de análise sobre a conversa social sobre coronavirus desenvolvida pela comunidade ibero-americana no Instagram desde a perspetiva do Big Data. Ficariam por resolver questões sobre quem foram os nós principais desta conversa, algo que será apresentado em artigos futuros. Porém, ante as diversas urgências provocadas pela pandemia, a comunicação ocupa uma posição fundamental e urge o compartilhamento parcial dos resultados obtidos na investigação. 
Sanz-Marcos, P. Brand management y tribu consumidora. Un estudio aplicado a las marcas de surf españolas

\section{REFERENCIAS}

Agrosino, M. (2009). Etnografia e observação participante. Porto Alegre: Artmed.

Aleixandre-Benavent, R.; Castelló-Cogollos, L. y Valderrama-Zurián, J.C. (2020). Información y comunicación durante los primeros meses de Covid-19. Infodemia, desinformación y papel de los profesionales de la información, en Profesional de la información, 29 (4). https://doi.org/10.3145/epi.2020.jul.08 .

Augé, M. (1994). Le sens des autres. Actualité de l'anthropologie. Paris: Fayard.

Barrientos-Báez, A., Martínez-Sala, A., Altamirano, V. y Caldevilla-Domínguez, D. (2021). Fake News: La pandemia de la covid-19 y su cronología en el sector turístico. Historia y Comunicación Social, 26(Especial), 135-148. https://doi.org/10.5209/hics.74248

Bauman, Z. (2001). Modernidade líquida. Tradução de Plínio Dentzien. Rio de Janeiro: Jorge Zahar Editores.

Caldevilla-Domínguez, D., Barrientos-Báez, A. y Padilla-Castillo, G. (2021). Twitter as a tool for citizen education and sustainable cities after COVID-19, en Sustainability, 13 (6), 3514. https://doi.org/10.3390/su13063514

Casero-Ripollés, Andreu (2020). Impacto del Covid-19 en el sistema de medios. Consecuencias comunicativas y democráticas del consumo de noticias durante el brote, en El profesional de la información, 29(2). https://doi.org/10.3145/epi.2020.mar.23

Castells, M. (2000). A Sociedade em rede. São Paulo: Paz e Terra.

Castells, M. (2013). Redes de indignação e esperança: movimentos sociais na era da internet. Rio de Janeiro: Zahar.

Castillo-Esparcia, A.; Fernández-Souto, A.B.; Puentes-Rivera, I. (2020). "Comunicación política y Covid-19. Estrategias del Gobierno de España" , en Profesional de la información, 29(4), e290419. https://doi.org/10.3145/epi.2020.jul.19

Cho, H.; Silver, N.; Na, K.; Adams, D.; Luong, K. T. y C. Song (2018). Visual Cancer Communication on Social Media: An Examination of Content and Effects of \#Melanomasucks, en Journal of Medical Internet Research, 20(9). https://doi.org/10.2196/10501.

Chung, C.F.; Agapie, E., Schroeder, J.; Mishra, S.; Fogarty, J. y S. A. Munson (2017). When personal tracking becomes social: Examining the use of instagram for healthy eating. Proceedings of the SIGCHI Conference on Human Factors in Computing Systems, 2017, 674-1687. https://doi.org/10.1145/3025453.3025747. 
Sanz-Marcos, P. Brand management y tribu consumidora. Un estudio aplicado a las marcas de surf españolas

CrowdTangle Team (2020). "CrowdTangle". Menlo Park, USA: Facebook. https://apps.crowdtangle.com/universidaddevigoFacebook/lists/1383106

Dafonte-Gómez, Martínez-Rolán \& Corbacho-Valencia (2019). Mapa de los factcheckers ibero-americanos: presencia en redes y vías de difusión de contenidos. En Versuti et al. (eds), Medios e Transformação Social, 198-217. Aveiro: Ría Editorial

Fontcuberta, J. (2011, maio 11). Por un manifiesto postfotográfico. La Vanguardia. https://bit.ly/3d0ipKr

Fregber, K.; Graham, K. ; McGaughey, K. y L.A. Freberg (2011). Who are the social media influencers? A study of public perceptions of personality?, en Public Relations Review, 37, 90-92. https://doi.org/10.1016/j.pubrev.2010.11.001

Fung, I. C. H.; Blankenship, E. B.; Ahweyevu, J. O.; Cooper, L. K.; Duke, C. H., Carswell, S. L.; ... y Z. T. H. Tse (2020). Public health implications of image-based social media: A systematic review of Instagram, Pinterest, Tumblr, and Flickr. The Permanente Journal, 24. https://doi.org/10.7812/TPP/18.307.

Fung, I. C. H.; Blankenship, E. B.; Goff, M. E.; Mullican, L. A.; Chan, K. C., Saroha, N., ... y Z. T. H. Tse (2017). Zika-virus-related photo sharing on Pinterest and Instagram, en Disaster medicine and public health preparedness, 11(6), 656-659.

Garcia, A., y Eiró-Gomes, M. (2020). O papel da comunicação: a utilização das redes sociais nos cuidados de saúde primários, en Comunicação E Sociedade, 197-217. https://doi.org/10.17231/comsoc.0(2020).2747

Graphext (s.f). The overview. https://www.graphext.com/docs/the-overview

Guidry, J. P.; Carlyle, K. E.; LaRose, J. G.; Perrin, P.; Messner, M. y M. Ryan, (2019). Using the health belief model to analyze Instagram posts about Zika for public health communications, en Emerging infectious diseases, 25(1). https://doi.org/10.3201/eid2501.180824

Guidry, J.; Yan Jin, C.; Marcus Messner, A.O. y S. Meganck (2017). Ebola on Instagram and Twitter: How health organizations address the health crisis in their social media engagement, en Public Relations Review. 46 (3), 477-486. https://doi.org/10.1016/j.pubrev.2017.04.009

Hung, M.; Lauren, E.; Hon, E.S.; Birmingham W.C.; Xu, J.; Su, S.; Hon, S.D.; Park, J.; Dang, P. y M. S. Lipsky (2020). Social Network Analysis of COVID-19 Sentiments: Application of Artificial Intelligence, en Journal of Medical Internet Research, 22 (8). https://doi.org/10.2196/22590

Igartua, J.J.; Ortega-Mohedano, F. y C. Arcila-Calderón (2020). The uses of communication in the time of coronavirus. A cross-cultural study, en El profesional de la información, 29 (3). https://doi.org/10.3145/epi.2020.may.18 
Sanz-Marcos, P. Brand management y tribu consumidora. Un estudio aplicado a las marcas de surf españolas

Jenkins, H. (2009). A cultura da convergência. São Paulo: Editora Aleph.

Kamel Boulos, M.N.; Giustini, D.M. y S. Wheeler (2016). Instagram and WhatsApp in Health and Healthcare: An Overview Journals, en Future Internet, 8 (3). https://doi.org/10.3390/fi8030037

Levy, P. (2010) Cibercultura. Tradução de Carlos Irineu da Costa. São Paulo: Editora 34.

Lucibello, K. M., Vani, M. F., Koulanova, A., deJonge, M. L., Ashdown-Franks, G., \& Sabiston, C. M. (2021). \#quarantine15: A content analysis of Instagram posts during COVID-19, en Body Image, 38, 148-156.

Martínez-Rolán, X., Tymoshchuk, O., Piñeiro-Otero, T., Renó, D. (2019). Instagram como red de promoción e hipermediación del turismo rural: el caso de Aldeias Históricas, en Revista Latina de Comunicación Social, 74, 1610-1632. https://doi.org/10.4185/RLCS-2019-1401

Marwick, A. E. (2015). Instafame: luxury selfies in the attention economy, en Public Culture, $27(1$ (75)), 137-160. https://doi.org/10.1215/08992363-2798379

McLuhan, M. (1964). Understanding Media - the extensions of man. New York: McGraw-Hill.

Niknam, F., Samadbeik, M., Fatehi, F., Shirdel, M., Rezazadeh, M., \& Bastani, P. (2021). COVID-19 on Instagram: A content analysis of selected accounts, en Health Policy and Technology, 10, 1, 165-173.

Orduña-Malea, E., Font-Julián, C. I., \& Ontalba-Ruipérez, J.-A. (2020). Covid-19: análisis métrico de vídeos y canales de comunicación en YouTube, en Profesional De La Información, 29, 4. https://doi.org/10.3145/epi.2020.jul.01

Pinto, P. A., Brasileiro, F. S., Antunes, M. J. L. y Almeida, A. M. P. (2020). CoVID-19 no Instagram: práticas de comunicação estratégica das autoridades de saúde durante a pandemia, en Comunicação Pública, 15(29). https://doi.org/10.4000/cp.11288

Público (2020, 21 agosto). Fernando Simón anima a los influencers a ayudar a controlar la epidemia. Recuperado de https://bit.ly/2LrM9o3

Rambukkana N. (2015). Hashtag publics: the power and politics of discursive networks. New York: Peter Lang.

Rovetta, A., y Bhagavathula, A. S. (2020). Global infodemiology of COVID-19: analysis of Google web searches and Instagram hashtags, en Journal of medical Internet research, 22(8). https://doi.org/10.2196/20673

Santaella, L. (2005) Matrizes da linguagem e pensamento: sonora, visual, verbal: aplicações na hipermídia. São Paulo: Iluminuras e FAPESP. 
Sanz-Marcos, P. Brand management y tribu consumidora. Un estudio aplicado a las marcas de surf españolas

Santaella, L. (2013) Comunicação ubíqua: repercussões na cultura e na educação. São Paulo: Paulus.

Santos, B. S. (2005). A globalização e as ciências sociais. São Paulo: Cortez Editora.

Seltzer, E.; Jean, N.; Kramer-Golinkoff, E.; Asch, D. y R. Merchant (2015). The content of social media's shared images about ebola: a retrospective study, en Public health, 129(9). https://doi.org/10.1016/j.puhe.2015.07.025

Seltzer, E.;Hortst-Martz, E.; Lu, M. y R.M. Marchant (2017). Public sentiment and discourse about Zika virus on Instagram, en Public health 150, 170-175. https://doi.org/10.1016/j.puhe.2017.07.015

Sheldon, P. y K. Bryant 2016). Instagram: Motives for its use and relationship to narcissims and contextual age, en Computers in Human Behavior, 58, 89-97. https://doi.org/10.1016/j.chb.2015.12.059

Thompson, J. (2002). O escândalo político: o poder e visibilidade na era da mídia. Rio de Janeiro: Vozes.

Torres-Romay, E. y S. García Mirón (2020). Influencers y coronavirus. Los contenidos sobre la pandemia COVID-19 en las publicaciones de prescriptores de redes sociales en España (2020): el caso de Instagram, en Quaderns del CAC, 23(46), 81-91.

Turpo Gebera, O. W. (2008). La netnografía: un método de investigación en Internet, en Educar, 81-93, https://raco.cat/index.php/Educar/article/view/142550

Wagner, D.N., Marcon, A.R. y Caulfield, T. (2020)-. "Immune Boosting" in the time of COVID: selling immunity on Instagram, en Allergy Asthma Clin Immunol, 16 (76). https://doi.org/10.1186/s13223-020-00474-6

WeAreSocial \& Hootsuite (2021). Digital 2021 global overview. Recuperado de https://bit.ly/36OhFDU 


\section{AUTOR/ES:}

\section{Denis Renó:}

Periodista y documentalista, Doctor en Comunicación Social por la Universidad Metodista de São Paulo (Brasil), ha desarrollado post doctorado sobre Periodismo Transmedia por la Universidad Complutense de Madrid (España) y post doctorado sobre Interfaces Interactivas para dispositivos móviles por la Universidad de Aveiro (Portugal). Es profesor del Programa de Periodismo de la Facultad de Arquitectura, Artes y Comunicación de la Universidad Estadual Paulista - UNESP (Brasil), donde también es profesor del programa de postgrado en Televisión Digital. Además, es profesor del programa de postgrado en Periodismo de la Universidad Estadual de Ponta Grossa - UEPG (Brasil). Actualmente, es Director Académico de la Catedra Latinoamericana de Narrativa Transmedia y miembro del Media Ecology Association (EEUU), además de ser coordinador del Mobilab Research - Laboratorio de Estudios sobre Nuevas Narrativas y Dispositivos Móviles. El laboratorio es financiado por agencias de fomento de Brasil.

denis.reno@unesp.br

Orcid ID: https://orcid.org/0000-0003-0837-4261

Google Scholar: http://scholar.google.es/citations?user=n9FvBccAAAAJ\&hl=pt-BR

ResearchGate: https://www.researchgate.net/profile/Denis-Reno-2

Academia.edu: https://unesp.academia.edu/DenisPortoRenó

\section{Xabier Martínez-Rolán:}

Doctor en Comunicación por la Universidade de Vigo, premio extraordinario de doctorado y profesor en la Facultad de Ciencias Sociales y de la Comunicación en dicha universidad, donde coordina el Máster en Comunicación en Medios Sociales y Creación de Contenidos Digitales. Sus líneas de investigación se centran en el estudio de comunidades virtuales, uso y apropiación de redes sociales y nuevos formatos publicitarios, y fórmulas comunicativas en nuevos medios. Recientemente ha publicado Diseño de páginas web: Wordpress para todos los públicos (Editorial UOC). xabier.rolan@uvigo.es

Orcid ID: https://orcid.org/0000-0002-7631-2292

Google Scholar: https://scholar.google.com/citations?hl=es\&user=6U99DAQAAAA]

ResearchGate: https://www.researchgate.net/profile/Xabier Martinez-Rolan

Academia.edu: https://uvigo.academia.edu/XabierRolan

\section{Teresa Piñeiro-Otero:}

Doctora en Comunicación por la Universidade de Vigo y profesora en el Grado en Comunicación Audiovisual de la Universidade da Coruña. Ha orientado su investigación hacia las nuevas manifestaciones comunicativas especialmente en el ámbito del sonido, las estrategias multimedia o las narrativas transmedia. En esta línea es autora de numerosas contribuciones en revistas y editoriales de impacto. Recientemente ha publicado Sonidos que cuentan. La ambientación sonora audiovisual (Editorial UOC). 
Sanz-Marcos, P. Brand management y tribu consumidora. Un estudio aplicado a las marcas de surf españolas

teresa.pineiro@udc.es

Orcid ID: https://orcid.org/0000-0001-6414-2700

Google Scholar: https://scholar.google.com/citations?user=4hOLIbUAAAAJ\&hl=es

ResearchGate: https://www.researchgate.net/profile/Teresa Pineiro-Otero

Academia.edu: https://coruna.academia.edu/TeresaPi\%C3\%B1eiro

\section{Andrea Versuti:}

Doutora em Educação Ciência e Tecnologia pela UNICAMP. Professora da área de Educação, Tecnologias e Comunicação da Faculdade de Educação da Universidade de Brasília (UnB). Docente do Programa de Pós-Graduação em Educação (FE/UnB). Pósdoutoranda no Programa de Pós-Graduação em Mídia e Tecnologia da UNESP Bauru, sob a supervisão do Prof. Dr. Denis Porto Renó. Membro do Grupo de Pesquisa Educação, Filosofia e Imagem (GEFI). andrea.versuti@gmail.com

Orcid ID: https://orcid.org/0000-0002-3150-5015

Google Scholar: https://scholar.google.es/citations?hl=es\&user=MzIwDNwAAAA]

ResearchGate: https://www.researchgate.net/profile/Andrea-Versuti

Academia.edu: https://brasilia.academia.edu/AndreaVersuti 